\title{
Atividade do óleo essencial de Eucalyptus Globulus no controle de bactérias da cavidade oral
}

\author{
Activity of Eucalyptus Globulus essential oil in the control of bacteria in the oral cavity
}

Actividad del aceite esencial de Eucalyptus Globulus en el control de bacterias en la cavidad bucal

Recebido: 31/08/2021 | Revisado: 08/09/2021 | Aceito: 23/10/2021 | Publicado: 24/10/2021

Nathália Frade Monteiro

ORCID: https://orcid.org/0000-0002-3367-1631 Centro Universitário UniFacid, Brasil

E-mail: chicaovet@gmail.com

Helena Maria Reinaldo Lima

ORCID: https://orcid.org/0000-0003-4892-9137 Centro Universitário UniFacid, Brasil

E-mail: helenareinaldo@ hotmail.com

Francisco Laurindo da Silva

ORCID: https://orcid.org/0000-0001-6837-4509 Centro Universitário UniFacid, Brasil E-mail: flspb@yahoo.com.br

Francisco das Chagas Araújo Sousa

ORCID: https://orcid.org/0000-0001-7244-9729

Universidade Estadual do Piauí, Brasil

E-mail: franciscoaraujo@ccs.uespi.br

Wenderson Costa da Silva

ORCID: https://orcid.org/0000-0001-6031-9775

Universidade Estadual do Maranhão, Brasil

E-mail: wendersoncosta09@hotmail.com

Liana Cynthia de Macedo Reis

ORCID: https://orcid.org/0000-0001-7304-7713

Instituto Federal do Piauí, Brasil E-mail: lianareis@ifpi.edu.br

Alice de Castro Cruz Pimentel

ORCID: https://orcid.org/0000-0002-4825-0362

Universidade Estadual do Maranhão, Brasil

E-mail:kas201587@outlook.com

Daniel Rodrigues Furtado

ORCID: https://orcid.org/0000-0002-8122-182X

Universidade Estadual do Maranhão, Brasil

E-mail: danielrodrigues.d1234@gmail.com

Augusto Cesar Evelin Rodrigues

ORCID: https://orcid.org/0000-0001-7469-981X

Centro Universitário UniFacid, Brasil

E-mail: augustocevelin@yahoo.com.br

Renan Paraguassu de Sá Rodrigues

ORCID: https://orcid.org/0000-0002-8108-4669

Universidade Federal do Piauí, Brasil

E-mail: renanparaguasu@ hotmail.com

Adrielle Martins Monteiro Alves

ORCID: https://orcid.org/0000-0002-1661-9399

Aespi Ensino Superior do Piauí, Brasil

E-mail: adriellemonteiro@hotmail.com

João Pedro Pio Rodrigues

ORCID: https://orcid.org/0000-0002-4218-2071 Aespi Ensino Superior do Piauí, Brasil E-mail: joao.pedro.pio@ hotmail.com

Amanda Laurindo Monteiro

ORCID: https://orcid.org/0000-0002-4832-4544 Centro Universitário UniFacid, Brasil E-mail: amandalaurindo_@hotmail.com

\section{Resumo}

O óleo de Eucalyptus globulus, apresenta diversas propriedades farmacológicas. Dentre elas, destacam-se seus efeitos antissépticos, expectorantes, antifúngicos e antimicrobiano. Diante disto o presente trabalho teve o objetivo geral de 
avaliar a atividade do óleo de Eucalyptus globulus no controle de bactérias da cavidade oral e objetivos específicos de comparar o efeito o óleo de Eucalyptus globulus com efeito da clorexidina e determinar em quais cepas bacterianas o óleo de Eucalyptus globulus apresentava maior eficácia. A atividade antimicrobiana foi testada in vitro, em bactérias do grupo Escherichia coli (E. coli), Enterococcus faecalis (E. faecalis) e Staphylococcus aureus (S. aureus) pelo método de difusão em ágar com a técnica de poços. Os poços foram preenchidos com as soluções de clorexidina 0,12\% e óleo de Eucalyptus globulus em concentrações de 100\%, 50\%, 25\%, 10\%, $1 \%$ e 0,1\% com a finalidade de comparar o efeito antimicrobiano pela inibição do crescimento. Os testes aconteceram em triplicata e a análise estatística foi realizada através do teste $T$ de Student. Os dados foram organizados em tabelas para a demonstração dos resultados obtidos. Considerou-se como significante valores de $p<0,05$. Observou-se que o óleo de Eucalyptus globulus nas concentrações de $100 \%, 50 \%, 25 \%$ e $10 \%$ de maneira geral em todas as bactérias apresentaram efetividade semelhante ao da clorexidina. Pode-se concluir que o óleo de Eucalyptus globulus em suas variadas concentrações, apresentaram efeitos antimicrobianos, sua efetividade foi tão boa quanto o da clorexidina e em todas as cepas bacterianas estudadas este óleo apresentou ação antimicrobiana.

Palavras-chave: Eucalyptus globulus; Antibacterianos; Fitoterapia.

\begin{abstract}
Eucalyptus globulus oil has several pharmacological properties. Among them, its antiseptic, expectorant, antifungal and antimicrobial effects stand out. The present work had the general objective of evaluating the activity of Eucalyptus globulus oil in the control of bacteria of the oral cavity and specific objectives to compare the effect of Eucalyptus globulus oil with chlorhexidine effect and to determine in which bacterial strains the oil of Eucalyptus globulus was more effective. The antimicrobial activity was tested in bacteria of the group Escherichia coli (E. coli), Enterococcus faecalis (E. faecalis) and Staphylococcus aureus (S. aureus) by the agar diffusion method with the well technique. The wells were filled with solutions of $0.12 \%$ chlorhexidine and Eucalyptus globulus oil in concentrations of $100 \%, 50 \%, 25 \%, 10 \%, 1 \%$ and $0.1 \%$ in order to compare the antimicrobial effect by inhibition growth. The tests were performed in triplicate and the statistical analysis was performed using Student's T-test. The data were organized into tables for the demonstration of the results obtained. Values of $p<0.05$ were considered significant. It was observed that Eucalyptus globulus oil at concentrations of $100 \%, 50 \%, 25 \%$ and $10 \%$ in general in all bacteria presented similar effectiveness to that of chlorhexidine. It is possible to conclude that Eucalyptus globulus oil in its varied concentrations, presented antimicrobial effects, its effectiveness was as good as that of chlorhexidine and in all bacterial strains studied, this oil presented antimicrobial action.
\end{abstract}

Keywords: Eucalyptus globulus; Anti-bacterial agents; Phytotherapy.

\title{
Resumen
}

El aceite de eucalipto globulus tiene varias propiedades farmacológicas. Entre ellos destacan sus efectos antisépticos, expectorantes, antifúngicos y antimicrobianos. Por tanto, el presente trabajo tuvo como objetivo general evaluar la actividad del aceite de Eucalyptus globulus en el control de bacterias en la cavidad bucal y objetivos específicos de comparar el efecto del aceite de Eucalyptus globulus con el efecto de la clorhexidina y determinar en qué cepas bacterianas el aceite de Eucalyptus globulus fue más eficaz. La actividad antimicrobiana fue probada in vitro en bacterias del grupo Escherichia coli (E. coli), Enterococcus faecalis (E. faecalis) y Staphylococcus aureus $(S$. aureus) por el método de difusión en agar con la técnica de pocillo. Los pozos se llenaron con soluciones de clorhexidina al $0,12 \%$ y aceite de Eucalyptus globulus en concentraciones de $100 \%, 50 \%, 25 \%, 10 \%, 1 \%$ y $0,1 \%$ para comparar el efecto antimicrobiano por inhibición del crecimiento. Las pruebas se realizaron por triplicado y el análisis estadístico se realizó mediante la prueba t de Student. Los datos se organizaron en tablas para demostrar los resultados obtenidos. Los valores de $p<0,05$ se consideraron significativos. Se observó que el aceite de Eucalyptus globulus a concentraciones de $100 \%, 50 \%, 25 \%$ y $10 \%$, en general, en todas las bacterias mostró una efectividad similar a la de la clorhexidina. Se puede concluir que el aceite de Eucalyptus globulus en sus variadas concentraciones tuvo efectos antimicrobianos, su efectividad fue tan buena como la de la clorhexidina y en todas las cepas bacterianas estudiadas este aceite presentó acción antimicrobiana.

Palabras clave: Eucalyptus globulus; Antibacterianos; Fitoterapia.

\section{Introdução}

As doenças mais prevalentes do meio oral, cárie dentária e doença periodontal, são de origem bacteriana, e atualmente constatou-se um aumento considerável no número de microrganismos resistentes aos antissépticos e antibióticos convencionais (Darwish \& Aburjai, 2010).

Segundo Pogue, Kaye, Cohen e Marchaim (2015) “A utilização frequente de antimicrobianos comerciais levam ao aparecimento de bactérias resistentes aos medicamentos". Na odontologia um dos antimicrobianos mais utilizados é a 
clorexidina. Essa substância é utilizada em formulações antissépticas. É uma biguanida catiônica que age principalmente sobre bactérias Gram-positivas, além de leveduras e dermatófitos (Kayaoglu et al., 2011).

Uma outra alternativa antimicrobiana são as plantas medicinais, que são utilizadas ao longo de gerações. Antes mesmo da escrita, os homens já apresentavam conhecimento sobre as plantas que eram medicinais e daquelas que poderiam ser usadas na alimentação (Bairwa, Gupta P., Gupta V., \& Srivastava, 2012).

Os componentes essenciais das plantas medicinais ou óleos essenciais, apresentam eficácia na terapêutica de doenças infecciosas. Essas substâncias, geralmente, são agentes com atividade antimicrobiana contra um grande número de microrganismos, incluindo espécies resistentes a antibióticos e antifúngicos. A abrangência da utilização de óleos essenciais é vasta e engloba fins variados, incluindo cuidados em relação à saúde bucal (Andrade, Fardin, Xavier, \& Nunes, 2011).

O Eucalyptus globulus pertence à família myrtaceae, e dentre seus principais efeitos encontra-se o de ação cicatrizante, anti-inflamatória e antimicrobiana. Por muitos anos essa espécie tem sido destinada a produção de fármacos inalantes, estimulantes de secreção nasal e em produtos de higiene bucal (Warnke et al., 2009).

Atualmente o uso indiscriminado de medicações industrializadas vem ocasionando resistência microbiana, por conta disso os agentes antimicrobianos naturais chamam atenção de pesquisadores, pela sua eficácia e baixo custo. É importante enfatizar que o óleo de Eucalyptus globulus apresenta ação antimicrobiana e antifúngica, portanto justifica-se a pesquisa sobre a eficácia deste óleo frente as bactérias da cavidade oral como uma alternativa na odontologia.

O objetivo geral do estudo foi avaliar a atividade do óleo de Eucalyptus globulus no controle de bactérias da cavidade oral. E especificamente comparar o efeito o óleo de Eucalyptus globulus com efeito da clorexidina e determinar em quais cepas bacterianas o óleo de Eucalyptus globulus apresentava maior eficácia.

\section{Metodologia}

\subsection{Tipo de Estudo}

Trata-se de um estudo experimental, de natureza aplicada, de caráter explicativo com abordagem quantitativa. Nos métodos quantitativos geram conjuntos de dados que podem ser analisados por meio de técnicas matemáticas, como percentual, estatísticas e probabilidades, métodos numéricos, métodos analíticos e a geração de equações e / ou fórmulas matemáticas aplicáveis a qualquer processo (Sousa et al., 2021a; Sousa et al., 2021b; De Oliveira et al., 2020). A pesquisa foi realizada no laboratório de microbiologia de uma Instituição Privada de Ensino de Teresina-PI. Como amostra do estudo foi utilizado o óleo essencial de Eucalyptus globulus.

\subsection{Obtenção e Manutenção das Cepas Bacterianas}

A Sociedade Brasileira de Microbiologia recomenda o uso de cepas da American Type Culture Colletion (ATCC) para o controle de qualidade dos trabalhos com bactérias. Nesse estudo foram utilizadas cepas de S. aureus (ATCC 25923), E. coli (ATCC 25922) e E. faecalis (ATCC 29212) adquiridas comercialmente. As cepas estavam liofilizadas e antes dos testes foram hidratadas em soro fisiológico e mantidas em repouso por $1 \mathrm{~h}$. Após esse tempo, foram semeadas em placas de Petri com ágar Brain Heart Infusion (BHI). As placas foram incubadas em estufa BOD (Demanda Bioquímica de Oxigênio) por $48 \mathrm{~h}$. As bactérias foram replicadas sucessivamente em meios de cultura BHI com o objetivo de manter suas propriedades. Esse procedimento foi realizado enquanto foram feitos os testes de suscetibilidade (Sousa et al., 2020).

\subsection{Preparo dos meios de cultura para os testes de suscetibilidade}

As placas para os testes de suscetibilidade foram formadas de duas camadas, sendo a primeira composta por ágar-ágar e a segunda de ágar Muller-Hinton e inóculo bacteriano. Para a formação da primeira camada, composta de ágar-ágar foi 
utilizado 10,6 gramas do ágar diluídos em $300 \mathrm{ml}$ de água destilada, conforme recomendação do fabricante. A mistura foi agitada suavemente e levada ao bico de Bunsen até dissolução total no meio de cultura. Alíquotas de $15 \mathrm{ml}$ do meio foram colocadas em 15 tubos de ensaio e esterilizadas na autoclave à temperatura de $120^{\circ} \mathrm{C}$ por 15 minutos. Após esterilização as alíquotas foram entornadas em placas de Petri, com tamanho de 90 x $15 \mathrm{~mm}$ descartáveis e esterilizadas (Pleion ®), e postas em repouso até solidificação do meio de cultura.

A segunda camada foi composta de Ágar Muller-Hinton, para tanto, 3,6g de soluto foram diluídas em $300 \mathrm{ml}$ de água destilada. Alíquotas de $13 \mathrm{ml}$ desse meio, foram colocadas em 15 tubos de ensaio e esterilizadas na autoclave à temperatura de $120^{\circ} \mathrm{C}$ por 15 minutos.

\subsection{Preparo do inóculo bacteriano}

Por meio de uma alça de platina esterilizada foi realizada a inoculação dos microrganismos recentemente replicados, em 15 tubos de ensaio com $1 \mathrm{ml}$ de soro fisiológico a $0,9 \%$ e após a inoculação verificou-se a turbidez com base na escala 0,5 de McFarland.

McFarland é uma escala nefelométrica de 11 tubos, numerada de 0,5 a 10, cujo padrão de turvação é o mais frequentemente utilizado nos laboratórios de microbiologia em diversos países, para determinar a intensidade de multiplicação bacteriana em meios de cultivo líquidos. A multiplicação bacteriana se opõe à passagem da luz, o que provoca a turvação e a opacificação do meio. Quanto maior o número de bactérias presentes na amostra, maior será o grau de turvação do meio de cultura. Recomendada pela Clinical and Laboratory Standards Institute (CLSI, 2018) nos Estados Unidos, a escala nefelométrica de McFarland foi adotada e também recomendada pela ANVISA no Brasil. Com essa regulamentação, é possível estabelecer um padrão que pode ser aferido em qualquer local do país, tornando a leitura de seus resultados correspondente (Scalia, Dolci, Ueda, \& Sassagawa, 2015).

\subsection{Preparo das placas para a realização dos testes de suscetibilidade}

Para a realização dos testes de suscetibilidade, pipetou-se $1 \mathrm{ml}$ da suspensão bacteriana e em seguida foi adicionado aos $13 \mathrm{ml}$ de ágar Muller-Hinton, mantido à temperatura de $45^{\circ} \mathrm{C}$ no banho-maria.

A segunda camada (composta de ágar Muller-Hinton e suspenção bacteriana) foi entornada sobre a primeira (ágarágar) e poços foram confeccionados na segunda camada, mediante a utilização de ponteiras plásticas esterilizadas de 6,0 mm de diâmetros. Após a confecção dos poços, as substâncias a serem testadas foram pipetadas e colocadas em cada poço.

\subsection{Atividade antibacteriana do óleo essencial de Eucalyptus globulus pelo método de difusão em ágar}

Todos os ensaios foram realizados em triplicata utilizando-se cepas da American Type Culture Collection (ATCC): E. coli (ATCC 25922) e S. aureus (ATCC 25923) e E. faecalis (ATCC 29212). A determinação da atividade antibacteriana foi realizada pela técnica da difusão em ágar em poços, segundo Groove e Randall (1955 como citado em Ramachandran, Senthilkumar, \& Vinothkumar, 2014). Como controle positivo utilizou-se um antisséptico, a clorexidina na concentração de $0,12 \%$.

Nos poços formados na segunda camada foram adicionados $40 \mu \mathrm{L}$ do óleo de Eucalyptus globulus. As placas foram incubadas a temperatura de $36^{\circ} \mathrm{C}$ em estufa BOD por $48 \mathrm{~h}$. Após período de incubação foi realizada a leitura dos resultados, que consistiu em medir o diâmetro dos halos de inibição formados, com auxílio de uma régua milimetrada.

Segundo a CLSI (2018) os halos de inibição podem variar de acordo com a metodologia utilizada assim como as concentrações, porém faz uma correlação entre o tipo de bactéria em estudo e os antimicrobianos sintéticos, para que possa ser feita uma mensuração dos valores encontrados e determinar se houve ou não inibição de crescimento. Foi considerado, como 
resultado final do óleo, a média das três medidas e, como suscetível a formação de halo com diâmetro igual ou superior a 8 $\mathrm{mm}$.

\subsection{Determinação da atividade antimicrobiana do óleo de Eucalyptus globulus em diluições seriadas}

A determinação da atividade antimicrobiana do óleo de Eucalyptus globulus em diluição seriada foi realizada conforme recomendada pelo CLSI (2018) com as mesmas bactérias utilizadas nos testes de difusão em ágar. O óleo foi diluído em DMSO nas concentrações de 1/2, 1/4, 1/10, 1/100 e 1/1000. Em cada orifício da placa teste foram micropipetados $40 \mu \mathrm{L}$ de própolis em diluição seriada. As placas foram incubadas a $36^{\circ} \mathrm{C}$ por $48 \mathrm{~h}$ sem agitação. Após período de incubação foi realizada a leitura dos resultados, que consistiu em medir o diâmetro dos halos de inibição formados. Os halos de inibição do crescimento bacteriano foram medidos conforme especificados anteriormente.

\subsection{Organização e Análise de dados}

Os dados foram analisados usando Statistical Package for the Social Sciences (SPSS, Chicago, IL, EUA.), Versão 20.0. Realizou-se análise descritiva dos dados, apresentando-os com média, desvio padrão. Para verificar o padrão de normalidade das variáveis realizou-se o teste Kolmogorov-Smirnov. Verificou-se que as variáveis seguiram o padrão de normalidade com valor de $p$ do teste maior que 0,05. Assim, os testes selecionados para as associações foram os testes $T$ Student e ANOVA. Considerou-se como significante valores de $p<0,05$.

O presente estudo não foi submetido ao Comitê de Ética e Pesquisa (CEP) porque não envolveu seres humanos ou animais. As bactérias utilizadas nessa pesquisa foram cepas industrializadas.

\section{Resultados e Discussão}

Neste estudo foi avaliado in vitro o efeito da clorexidina $0,12 \%$ e do óleo de Eucalyptus globulus em cepas das bactérias: S. aureus, E. coli e E. faecalis em função destes microrganismos serem alguns dos principais responsáveis pela etiologia de doenças bucais.

O óleo de Eucalyptus globulus adquirido comercialmente encontrava-se na concentração de 100\%. A amostra foi diluída nas proporções: 1/2,1/4,1/10,1/100 e 1/1000, e obteve-se soluções com concentrações equivalente a 50\%, 25\%, 10\%, $1 \%$ e $0,1 \%$.

De acordo com os resultados obtidos em valores de diâmetros em milímetros dos halos de inibição, as amostras do óleo de Eucalyptus globulus apresentaram atividade antimicrobiana em todas as bactérias estudadas (Gráfico 1). A clorexidina a $0,12 \%$ foi utilizada como grupo de controle positivo, com atividade antimicrobiana para todas as bactérias analisadas. A água destilada, por não possuir efeito antimicrobiano, foi usada como controle negativo. 
Gráfico 1. Média de inibição do halo bacteriano para diferentes tipos de soluções. Teresina, PI, Brasil, 2018.

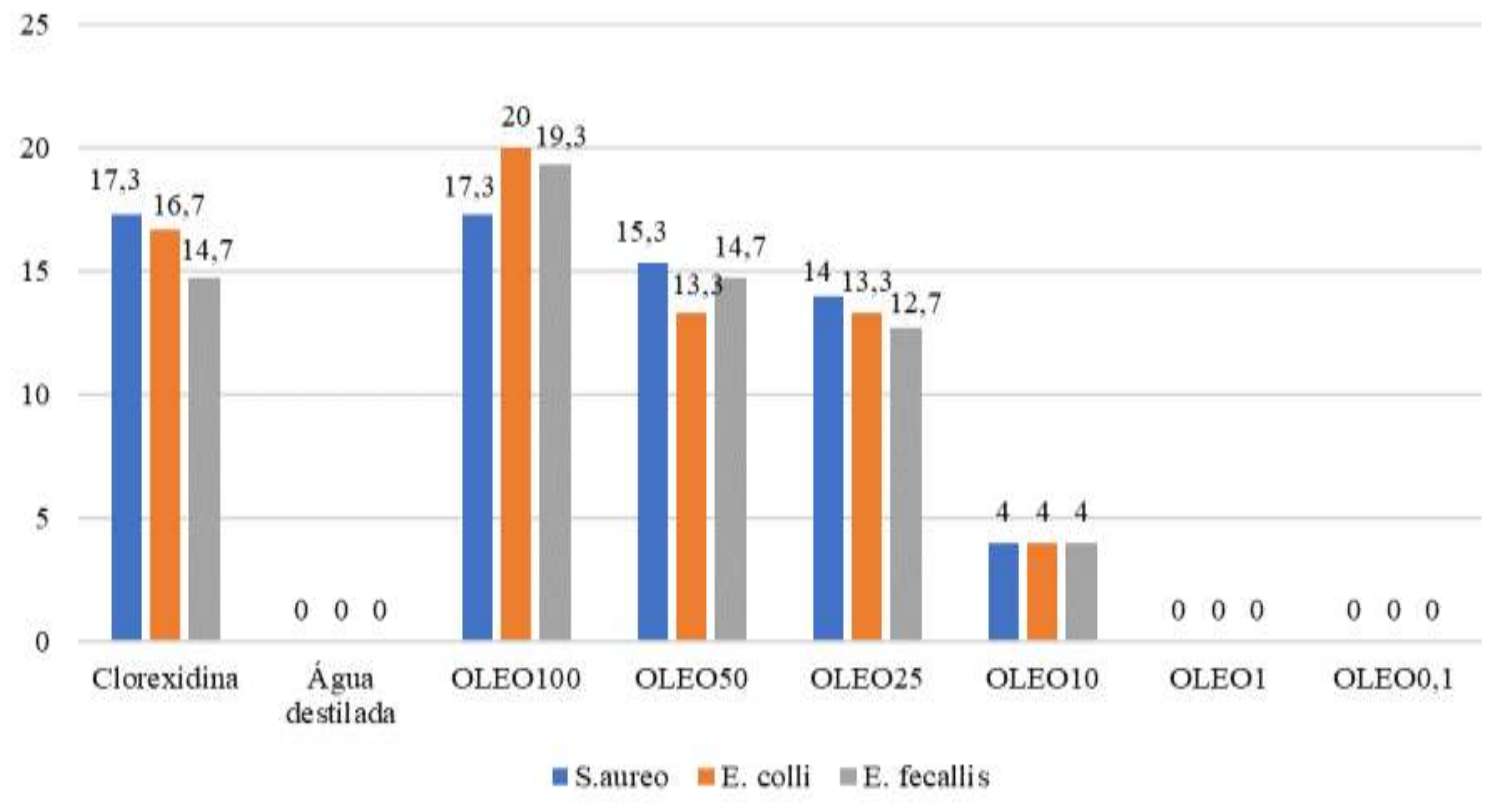

Fonte: Autores (2018).

Ao analisar a média dos halos de inibição presente no Gráfico 1 verificou-se que todas bactérias estudadas, apresentaram ação antimicrobiana com maior efetividade na bactéria E. coli e menor na bactéria E. faecalis. Além disso o efeito foi semelhante ao da clorexidina a 0,12\% em todas as bactérias, dados que contestam o estudo de Mota, Taurino e Provenda (2015) onde a efetividade do óleo foi superior ao da clorexidina em concentração de 0,5\%.

Segundo Mubita et al. (2008) a ação antibacteriana do óleo de Eucalyptus globulus está relacionada com o nível de 18 cineol presente na planta. Em geral o óleo apresenta de $79 \%$ a $85 \%$ desse composto, cuja percentual pode sofrer alteração devido aos processos de obtenção e armazenamento do mesmo. O óleo quando adquirido após o processo de destilação a vapor pode perder suas propriedades com o passar do tempo, o que justifica os resultados de Mota et al. (2015) apresentarem ação antimicrobiana superior uma vez que após a destilação do óleo, este foi imediatamente utilizado diferente do presente estudo onde a amostra foi adquirida no mercado e empregada após algum tempo.

Tabela 1. Associação entre clorexidina e diferentes concentrações de óleo para verificação da ação antibacteriano para $S$. aureus. Teresina, PI, Brasil, 2018.

\begin{tabular}{|c|c|c|c|c|c|}
\hline Variáveis & & $\mathbf{N}$ & Média & Desvio padrão & Valor de $p^{*}$ \\
\hline \multirow[t]{2}{*}{ Par 1} & Clorexidina & 3 & 14,7 & 1,2 & 0,222 \\
\hline & Óleo $100 \%$ & 3 & 19,3 & 4,2 & \\
\hline \multirow[t]{2}{*}{ Par 2} & Clorexidina & 3 & 14,7 & 1,2 & 1,000 \\
\hline & Óleo 50\% & 3 & 14,7 & 2,3 & \\
\hline \multirow[t]{2}{*}{ Par 3} & Clorexidina & 3 & 14,7 & 0,0 & - \\
\hline & Óleo 25 & 3 & 12,7 & 0,0 & \\
\hline \multirow[t]{2}{*}{ Par 4} & Clorexidina & 3 & 14,7 & 1,2 & 0,135 \\
\hline & Óleo $10 \%$ & 3 & 4,0 & 6,9 & \\
\hline \multirow[t]{2}{*}{ Par 5} & Clorexidina & 3 & 14,7 & 1,2 & 0,002 \\
\hline & Óleo $1 \%$ & 3 & 0,0 & 0,0 & \\
\hline \multirow[t]{2}{*}{ Par 6} & Clorexidina & 3 & 14,7 & 1,2 & 0,002 \\
\hline & Óleo $0.1 \%$ & 3 & 0,0 & 0,0 & \\
\hline \multirow[t]{2}{*}{ Par 7} & Clorexidina & 3 & 14,7 & 1,2 & 0,002 \\
\hline & Água destilada & 3 & 0,0 & 0,0 & \\
\hline
\end{tabular}

Fonte: Autores (2018). 
Através dos dados obtidos na Tabela 1, constatou-se que o óleo de Eucaliptus globulus (100\%, 50\% e 10\%) e a Clorexidina $0,12 \%$ apresentaram efeitos antimicrobianos. O óleo na concentração a $25 \%$ apresentou desvio padrão $(0,0)$ e por conta disto não foi possível realizar o teste estatístico nesta concentração. A água destilada e o óleo nas concentrações de $1 \%$ e de $0,1 \%$ não apresentaram efeito antimicrobiano uma vez que não houve formação do halo de inibição.

Quanto a bactéria S. aureus, $(p>0,05)$ constatou-se que o óleo nas concentrações a 100\%, 50\%, e 10\% exibiram o mesmo efeito antibacteriano que a clorexidina (Tabela 1).

Os resultados do presente estudo coincidem com a pesquisa de Clavijo-Romero, Quintanilla-Rarvajal e Ruiz (2018), em que o óleo essencial de Eucalyptus globulus demonstrou atividade antibactericida em 24 horas contra as bactérias E. coli, $S$. aureus e $P$. aeruginosa. Segundo os citados autores este óleo essencial foi considerado uma alternativa promissora para o uso em produtos químicos e medicamentos

No Gráfico 2, pôde-se observar que o óleo de Eucalyptus globulus nas concentrações de 100\%, 50\% e 10\% apresentaram ação antimicrobiana semelhante na clorexidina a $0,12 \%$. O halo de inibição do óleo na concentração a $100 \%$ foi maior que o da clorexidina, em contrapartida na concentração a $50 \%$ foi igual. No entanto nas concentrações de $25 \%$ e $10 \%$ o halo do óleo foi menor que o controle positivo.

Gráfico 2. Média de inibição de halo bacteriano para S. aureus para diferentes soluções antibacterianas. Teresina, PI, Brasil, 2018.

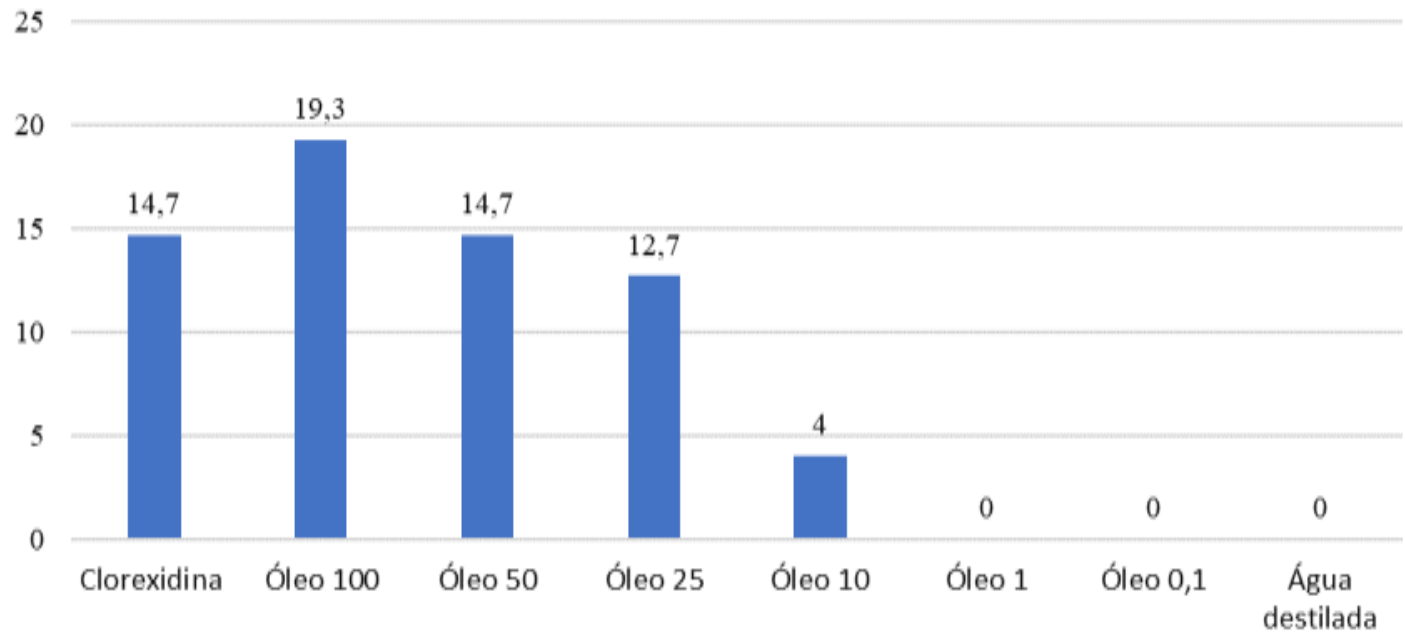

Fonte: Autores (2018).

No que diz respeito à atividade antimicrobiana contra E. coli, as amostras do óleo de Eucalyptus globulus demonstraram propriedades inibitórias nas concentrações de $100 \%, 50 \%, 25 \%$ e $10 \%$ possuindo o mesmo efeito antibacteriano que a clorexidina (valor de $p>0,05$ ) como visto na tabela 3. As amostras: óleo a 01\%, óleo a 0,1\% e água destilada não apresentaram atividade. 
Tabela 2. Associação entre clorexidina e diferentes concentrações de óleo para verificação da ação de inibição do halo bacteriano para E. coli. Teresina, PI, Brasil, 2018.

\begin{tabular}{|c|c|c|c|c|c|}
\hline Variáveis & & $\mathbf{N}$ & Média & Desvio padrão & Valor de $p^{*}$ \\
\hline \multirow[t]{2}{*}{ Par 1} & Clorexidina & 3 & 16,7 & 3,1 & 0,300 \\
\hline & Óleo $100 \%$ & 3 & 20,0 & 5,3 & \\
\hline \multirow[t]{2}{*}{ Par 2} & Clorexidina & 3 & 16,7 & 3,1 & 0,300 \\
\hline & Óleo $50 \%$ & 3 & 13,3 & 2,3 & \\
\hline \multirow[t]{2}{*}{ Par 3} & Clorexidina & 3 & 16,7 & 3,1 & 0,300 \\
\hline & Óleo $25 \%$ & 3 & 13,3 & 1,2 & \\
\hline \multirow[t]{2}{*}{ Par 4} & Clorexidina & 3 & 16,7 & 3,1 & 0,113 \\
\hline & Óleo $10 \%$ & 3 & 4,0 & 6,9 & \\
\hline \multirow[t]{2}{*}{ Par 5} & Clorexidina & 3 & 16,7 & 3,1 & 0,011 \\
\hline & Óleo $1 \%$ & 3 & 0,0 & 0,0 & \\
\hline \multirow[t]{2}{*}{ Par 6} & Clorexidina & 3 & 16,7 & 3,1 & $\mathbf{0 , 0 1 1}$ \\
\hline & Óleo 0.1 & 3 & 0,0 & 0,0 & \\
\hline \multirow[t]{2}{*}{ Par 7} & Clorexidina & 3 & 16,7 & 3,1 & $\mathbf{0 , 0 1 1}$ \\
\hline & Água destilada & 3 & 0,0 & 0,0 & \\
\hline
\end{tabular}

Fonte: Autores (2018).

No estudo de Bachir e Benali (2012), foi analisada a atividade antimicrobiana do óleo de Eucalyptus globulus em diferentes concentrações contra as bactérias S. aureus e E. coli. Os autores utilizaram as concentrações do óleo em $100 \%, 50 \%$ e $25 \%$ e como resultado verificaram que todas as concentrações do óleo foram eficazes contra as bactérias quando comparada a clorexidina. Foi constatado que a taxa de inibição foi maior nas bactérias Gram-negativas (E. coli) do que nas bactérias Grampositivas (S. aureus). Fato que pode ser explicado pelas diferenças estruturais nas paredes celulares desses microrganismos. Bactérias Gram-negativas apresentam uma parede quimicamente mais complexa proporcionando maior resistência (Araújo et al., 2010)

$\mathrm{Na}$ presente pesquisa verificou-se que o efeito antimicrobiano do óleo foi superior na E. coli em relação a $S$. aureus e a E. faecalis apenas na concentração a 100\%, contestando as pesquisas de Bachir e Benali (2012) e de Clavijo-Romero et al. (2018), uma vez que, em seus achados o halo formado na E. coli foi superior as demais bactérias analisadas em diferentes concentrações. Apesar dessas diferenças no tamanho do halo a ação antimicrobiana do óleo nas concentrações a 100\%, 50\%, $25 \%$ e $10 \%$ foi tão eficaz quanto a clorexidina.

Outro aspecto relevante que deve ser avaliado foi que na literatura não foi encontrado testes realizados com o óleo a $10 \%$ em bactérias. Neste estudo comprovou-se a atividade antimicrobiana na referida concentração.

De acordo com o Gráfico 3 o óleo de Eucalyptus globulus a 100\% apresentou maior halo comparado as demais diluições e a clorexidina e nas concentrações 50\%, 25\% e 10\% o halo desenvolvido foi menor que da clorexidina. Observou-se também que nas diluições de $1 \%$ e $0,1 \%$ não houve formação de halos. 
Gráfico 3. Média de inibição de halo bacteriano para E. coli para diferentes soluções antibacterianas. Teresina, PI, Brasil, 2018.

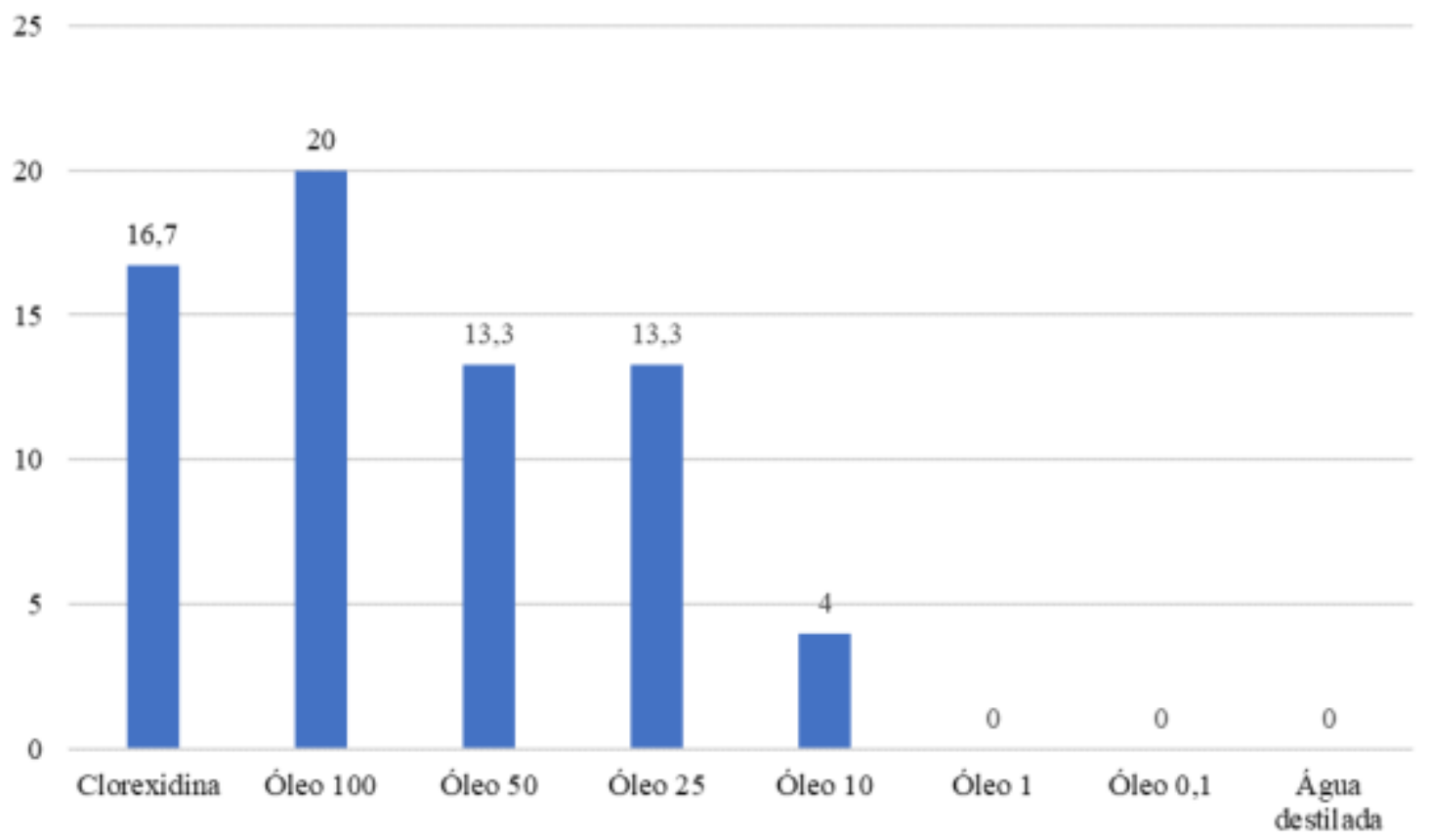

Fonte: Autores (2018).

Com relação ao Eucalyptus globulus (100\%, 50\%, 25\% e 10\%) e a Clorexidina 0,12\% constatou-se que apresentaram efeitos antimicrobianos quando testadas na bactéria E. faecalis. No entanto o óleo a $1 \%$ e a $0,1 \%$ não exibiram esta ação (Tabela 3).

Tabela 3. Associação entre clorexidina e diferentes concentrações de óleo para verificação da ação de inibição do halo bacteriano para E. faecalis. Teresina, PI, Brasil, 2018.

\begin{tabular}{|c|c|c|c|c|c|}
\hline Variáveis & & $\mathbf{N}$ & Média & Desvio padrão & Valor de $p^{*}$ \\
\hline \multirow[t]{2}{*}{ Par 1} & Clorexidina & 3 & 17,3 & 3,1 & 1,000 \\
\hline & Óleo 100\% & 3 & 17,3 & 1,2 & \\
\hline \multirow{2}{*}{ Par 2} & Clorexidina & 3 & 17,3 & 3,1 & 0,225 \\
\hline & Óleo $50 \%$ & 3 & 15,3 & 2,3 & \\
\hline \multirow[t]{2}{*}{ Par 3} & Clorexidina & 3 & 17,3 & 3,1 & 0,370 \\
\hline & Óleo 25\% & 3 & 14,0 & 2,0 & \\
\hline \multirow[t]{2}{*}{ Par 4} & Clorexidina & 3 & 17,3 & 3,1 & 0,081 \\
\hline & Óleo 10\% & 3 & 4,0 & 6,9 & \\
\hline \multirow[t]{2}{*}{ Par 5} & Clorexidina & 3 & 17,3 & 3,1 & $\mathbf{0 , 0 1 0}$ \\
\hline & Óleo $1 \%$ & 3 & 0,0 & 0,0 & \\
\hline \multirow{2}{*}{ Par 6} & Clorexidina & 3 & 17,3 & 3,1 & 0,010 \\
\hline & Óleo $0.1 \%$ & 3 & 0,0 & 0,0 & \\
\hline \multirow[t]{2}{*}{ Par 7} & Clorexidina & 3 & 17,3 & 3,1 & 0,010 \\
\hline & Água destilada & 3 & 0,0 & 0,0 & \\
\hline
\end{tabular}

Fonte: Autores (2018).

Deve-se ressaltar que na literatura não foi encontrado estudos relacionados do óleo de Eucalyptus globulus em Enterococcus faecalis, entretanto por ser uma bactéria prevalente no meio oral, esta foi incluída na pesquisa.

Observou-se no Gráfico 4 que o óleo de Eucalyptus gloobulus nas concentrações de 100\%, 50\%, 25\% e 10\% apresentaram ação antimicrobiana assim como na clorexidina a $0,12 \%$ contra a bactéria E. faecalis. Na concentração a $100 \%$ o 
halo de inibição do óleo foi igual ao da clorexidina $(17,3 \mathrm{~mm})$, nas concentrações de $50 \%$, $25 \%$ e $10 \%$ o halo foi menor. A água destilada assim como o óleo nas concentrações de $0,1 \%$ e $10 \%$ não apresentaram ação antibacteriana contra as cepas de E. faecalis.

Gráfico 4. Média de inibição de halo bacteriano para E. faecalis para diferentes soluções antibacterianas. Teresina, PI, Brasil, 2018.

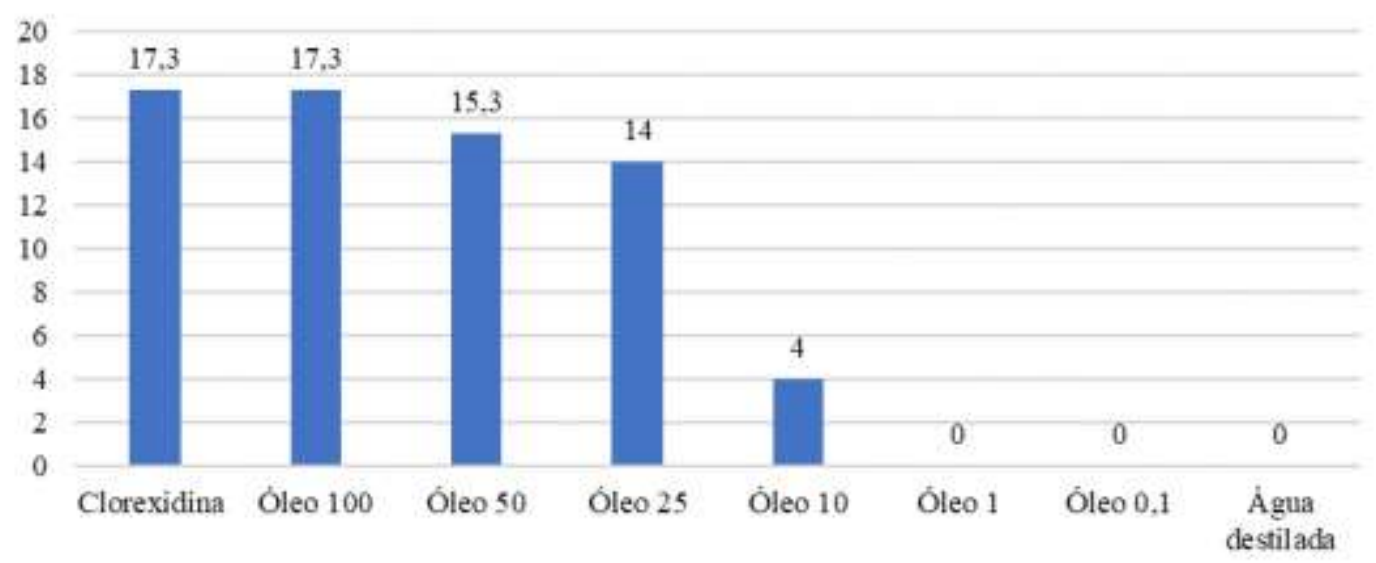

Fonte: Autores (2018).

No que tange as bactérias Staphylococcus aureus, Escherichia coli e Enterococcus faecalis verificou-se que a clorexidina, o óleo a 100\%, 50\%, 25\% e 10\% tiveram mesmo efeito antibacteriano conforme dados da Tabela 4.

Tabela 4. Associação do tipo de solução com o efeito de halo de inibição em diferentes bactérias. Teresina, PI, Brasil, 2018.

\begin{tabular}{lcccc}
\hline & $\begin{array}{c}\text { S.aureus } \\
\text { Média (desvio } \\
\text { padrão) }\end{array}$ & $\begin{array}{c}\boldsymbol{E} \text {. coli } \\
\text { Média (desvio } \\
\text { padrão) }\end{array}$ & $\begin{array}{c}\boldsymbol{E} \text {. faecalis } \\
\text { Média (desvio } \\
\text { padrão) }\end{array}$ & Valor de $\boldsymbol{p}$ \\
\hline Clorexidina & $17,3(3,0)$ & $16,7(3,0)$ & $14,7(1,2)$ & 0,467 \\
Água destilada & $0,0(0,0)$ & $0,0(0,0)$ & $0(0,0)$ & - \\
Óleo 100\% & $17,3(1,2)$ & $20,0(5,3)$ & $19,3(4,2)$ & 0,705 \\
Óleo 50\% & $15,3(2,3)$ & $13,3(2,3)$ & $14,7(2,3)$ & 0,587 \\
Óleo 25\% & $14,0(2,0)$ & $13,3(1,2)$ & $12,7(1,2)$ & 0,579 \\
Óleo 10\% & $4,0(6,9)$ & $4,0(6,9)$ & $4,0(6,9)$ & 1,000 \\
Óleo 1\% & $0,0(0,0)$ & $0,0(0,0)$ & $0(0,0)$ & - \\
Óleo 0,1\% & $0,0(0,0)$ & $0,0(0,0)$ & $0(0,0)$ & - \\
\hline
\end{tabular}

Teste Anova. Legenda: - teste não realizado, pois solução não inibiu bactérias. Fonte: Autores (2018).

Bachir e Benali (2012) concluíram em seu estudo que o óleo de Eucalyptus globulus é um bom candidato para explorar novos agentes antibacterianos alternativos para combater microrganismos patogênicos. Uma vez que em seu estudo foi comprovado a eficácia antimicrobiana da respectiva substância.

No presente trabalho o óleo de Eucalyptus globulus, quando comparada a clorexidina, apresentou ação antimicrobiana semelhante em diluições de até $10 \%$. Não foi encontrada pesquisa na literatura que compare ambas as substâncias em uma diluição do óleo a $10 \%$. Contudo, sabe-se que a clorexidina não pode ser utilizada a longo prazo pois este produto produz manchas nos dentes, alteração no paladar e o desenvolvimento da resistência microbiana (Agarwal, Nagesh, \& Murlikrishnan, 2010). Além disso a clorexidina é um antisséptico químico, o que segundo alguns autores, predispõe o surgimento de 
resistências bacterianas. Em contrapartida, por ser uma substância natural, o óleo de Eucalyptus globulus não apresenta nenhuma restrição quanto ao seu uso (Sheth, Kamath, Ramesh, \& Singla, 2013).

A comunidade odontológica está em constante busca de novos agentes terapêuticos que, além de terem um impacto positivo na saúde bucal, não terão os efeitos colaterais habituais dos antimicrobianos em uso. É importante ressaltar que tanto a clorexidina a $0,12 \%$ quanto o óleo de Eucalyptus globulus nas concentrações de 100\%, 50\%, 25\% e 10\% apresentaram atividade antimicrobiana contra as bactérias: S. aureus, E. coli e E. faecalis.

\section{Conclusão}

Com base nos dados obtidos e em relação aos parâmetros da análise adotados no estudo, pode-se concluir que: O óleo de Eucalyptus globulus apresentou atividade antimicrobiana eficaz no combate as principais bactérias da cavidade oral; A eficácia do óleo de Eucalyptus globulus nas concentrações estudadas foi tão eficaz quanto a clorexidina; e o óleo de Eucalyptus globulus apresentou eficácia igualitária no Staphylococcus aureus, Escherichia coli e Enterococcus faecalis.

\section{Referências}

Agarwal, P., Nagesh, L., \& Murlikrishnan. (2010). Evaluation of the antimicrobial activity of various concentrations of Tulsi (Ocimum sanctum) extract against Streptococcus mutans: an in vitro study. Indian Journal Of Dental Research, 21(3), 357-9.

Andrade, I. P., Fardin, R. F., Xavier, K. B. C., \& Nunes, A. P. F. (2011). Concentração inibitória mínina de antissépticos bucais em microorganismos da cavidade oral. Revista Brasileira de Pesquisa em Saúde, 13(1), 10-16.

Araújo, E. A., Andrade, N. J., Carvalho, A. F., Ramos, A. M., Silva, C. A. S., \& Silva, L. H. M. (2010). Aspectos coloidais da adesão de microorganismos. Química Nova, 33(9), 1940-1948.

Bachir, R. G., \& Benali, M. (2012). Antibacterial activity of the essential oils from the leaves of Eucalyptus globulus against Escherichia coli and Staphylococcus aureus. Asian Pacific Journal Of Tropical Biomedicine, 2(9), 739-742.

Bairwa, R., Gupta P., Gupta V. K., \& Srivastava, B. (2012). Traditional medicinal plants: Use in oral hygiene. Int J Pharm Chem Sci., 4, 1529-38.

Clavijo-Romero, A., Quintanilla-Carvajal, M. X., \& Ruiz, Y. (2018). Stability and antimicrobial activity of eucalyptus essential oil emulsions. Food Science And Technology International, 25(1), 24-37.

Clinical and Laboratory Standards Institute. Performance standard for antimicrobial susceptibility testing (28a ed). Annapolis Junction: CLSI.

Darwish, R. M., \& Aburjai, T. A. (2010). Effect of ethnomedicinal plants used in folklore medicine in Jordan as antibiotic resistant inhibitors on Escherichia coli. Bmc Complementary And Alternative Medicine, 10(1), 1-8.

De Oliveira, M. V. B., Oliveira, F. B. M., Silva, W. C., Mallet, J. R. S., Ferreira, N. S., Alves, F. R., \& Sousa, F. C. A. (2020). Fatores associados à perda do medo de infecção por HIV/AIDS em homens que fazem sexo com homens por meio de aplicativos de relacionamento. Revista Enfermagem Atual In Derme, $92(30), 1-12$

Kayaoglu, G., Ömürlü, H., Akca, G., Gürel, M., Gençay, Ö., Sorkun, K., \& Salih, B. (2011). Antibacterial Activity of Propolis versus Conventional Endodontic Disinfectants against Enterococcus faecalis in Infected Dentinal Tubules. Journal Of Endodontics, 37(3), $376-381$.

Mota, V. S., Turrini, R. N. T., \& Poveda, V. B. (2015). Antimicrobial activity of Eucalyptus globulus oil, xylitol and papain: a pilot study. Revista da Escola de Enfermagem da Usp, 49(2), 0216-0220.

Mubita, C., Syakalima, M., Chisenga, C., Munyeme, M., Bwalya, M., \& Chifumpa, G. \& Isogai, E. (2008). Antibiograms of faecal Escherichia coli and Enterococci species isolated from pastoralist cattle in the interface areas of the Kafue basin in Zambia. Veterinarski Arhiv, 78 (2), 179-185.

Pogue, J. M., Kaye, K. S., Cohen, D. A., \& Marchaim, D. (2015). Appropriate antimicrobial therapy in the era of multidrug-resistant human pathogens. Clinical Microbiology And Infection, 21(4), 302-312.

Ramachandran, A., Senthilkumar, M., \& Vinothkumar, D. (2014). Evaluation of Antimicrobial Activity of Leaf Extracts of Wattakaka Volubilis (L.) Stapf. International Journal of Engineering Research and Applications, 4, 6-10.

Scalia, R. A., Dolci, J. E. L., Ueda, S. M. Y., \& Sassagawa, S. M. (2015). In vitro antimicrobial activity of Luffa operculata. Brazilian Journal Of Otorhinolaryngology, 81(4), 422-430.

Sheth, H., Kamath, U., Ramesh, S., Singla, K. (2013). Comparison of the Antibacterial Efficacy of Tea Tree Oil with 3\% Sodium Hypochlorite and 2\% Chlorhexidine against E. faecalis: an in vitro study. Journal Of Contemporary Dentistry, 3(3), 117-120.

Sousa, F. C. A., Costa, C. E. O., Rodrigues, A. C. E. Siqueira, H. D. S., Siqueira, F. F. F. S., Silva, W. C., \& Reis, L. C. M. (2021b). Análise epidemiológica dos surtos de Doenças Transmitidas por Alimentos (DTAs) no estado do Piauí entre os anos de 2015 a 2019. Research, Society And Development, 10(7), e42610716756. 
Research, Society and Development, v. 10, n. 14, e59101420091, 2021

(CC BY 4.0) | ISSN 2525-3409 | DOI: http://dx.doi.org/10.33448/rsd-v10i14.20091

Sousa, F. C. A., Mineiro, A. C. B., Araújo, R. F. M., Oliveira, E. H., Silva, W. C., \& Coelho, L. S. (2020). Detecção de bactérias em diversos locais em um centro universitário de ciências da saúde. Research, Society And Development, 9(2), e120921966.

Sousa, F. C. A., Santos, I. G., Sousa, M. W., Silva, E. G., Santos, B. N. G., Medeiros, M. G. F., \& Siqueira, F. F. F. S. (2021a). Atividade antioxidante in vitro de Lippia origanoides H.B.K. Research, Society And Development, 10(8), e2810816716.

Warnke, P. H., Becker, S. T., Podschun, R., Sivananthan, S., Springer, I. N., Russo, P. A., Wiltfang, J., Fickenscher, H., \& Sherry, E. (2009). The battle against multi-resistant strains: renaissance of antimicrobial essential oils as a promising force to fight hospital-acquired infections. Journal of CranioMaxillofacial Surgery, 37(7), 392-397. 